\title{
VERIFICATION OF THERMO-TECHNICAL CHARACTERISTICS OF SELECTED FLOOR CONSTRUCTIONS FOR DAIRY COWS (PILOT STUDY)
}

\author{
Michaela NÉMETHOVÁ*, Jana LENDELOVÁ, Veronika ŠRANKOVÁ, Miroslav ŽITŇÁK, Lubomír BOTTO \\ Slovak University of Agriculture in Nitra, Slovakia
}

\begin{abstract}
The purpose of this study was to theoretically and practically investigate the thermo-technical properties of two bedding surface materials under real farm conditions during the hot summer period. The study was focused on the research of cubicles with water mattresses and straw bedding for dairy cows. The results of thermal-technical calculations showed that straw belongs to the category of warm floors, the thermal effusivity value of cubicle with straw is $b=173.55 \mathrm{~W} \cdot \mathrm{s}^{1 / 2} \cdot \mathrm{m}^{-2} \cdot \mathrm{K}^{-1}$; the heat transfer coefficient is $U=0.36 \mathrm{~W} \cdot \mathrm{m}^{-2} \cdot \mathrm{K}^{-1}$. Water mattress belongs to the category of cold floors with the thermal effusivity value $b=572.46 \mathrm{~W} \cdot \mathrm{s}^{1 / 2} \cdot \mathrm{m}^{-2} \cdot \mathrm{K}^{-1}$ and the heat transfer coefficient $U=4.504 \mathrm{~W} \cdot \mathrm{m}^{-2} \cdot \mathrm{K}^{-1}$. On the basis of calculations, the results showed that $U$ was 12.5 higher for water mattresses than for straw, and $b$ was 3.3 times higher for water mattresses than for straw. Based on thermographic measurements under field conditions of dairy farm, it was observed that the surface temperature of the water mattresses after one hour of lying was lower by $4.95 \pm 1.88^{\circ} \mathrm{C}$ in comparison to chopped straw. In practice, suitability of the material structure of water mattresses was verified on the basis of physical properties for summer period.
\end{abstract}

Keywords: water mattress; straw bedding; thermal conductivity; heat; dairy cows; summer period

Slovak climate conditions are intercontinental, however the number of tropical days in summer gradually increases. The summer period is accompanied with multiple negative effects, which are associated with the risk of severe heat load. The term heat stress is used widely and rather loosely, and may refer to the climate, climatic effects on the cattle, or cattle productive or physiologic responses (West, 2003). Health problems arising from the heat stress have been described in numerous studies (Cook et al., 2007; West, 2003; Kadzere et al., 2002). It is necessary to be aware that a cow itself generates a large amount of metabolic heat and accumulates an additional amount of heat from radiant heat source. Heat production and accumulation coupled with cooling capacity due to environmental conditions causes a heat increase to a point, at which the body temperature of cow increases, food intake decreases, and production and reproduction parameters deteriorate (West, 2003). There are several solutions to this issue - cooling of air, body of dairy cows, and surrounding materials. The interaction between the environment and the dairy is critical for general welfare and production. There is a wide range of possibilities for dairy housing (Kull et al., 2017). The dairy cattle spend most of the time lying and the surface on which they lie has already been described by multiple researchers (Tucker et al., 2003; Lendelová et al., 2009; Kull et al., 2017) as affecting the dairy cows in several ways. Cattle at dairy usually lie on straw; sawdust; sand; mattresses filled with recycled material; mattresses filled with rubber; and water mattresses. Studies that led to the effectiveness determination of individual technical-material solutions have highlighted the different conclusions. Recent research has shown that water mattresses are more preferred than mattresses filled with rubber (Wadsworth et al., 2015). The cattle with access to water filled mattresses spent a significantly lower amount of time lying and stood more in contrast to cows with access to sand beds and cattle kept at pasture (Margerison et al., 2014). The benefits of water mattresses lie in water incompressibility, which offers a nearly non-deformable bed and ability to co-ordinate the movement of mattress layers with the pressure of the joints during lying and reduce skin abrasions. The purpose of this study was to observe thermotechnical properties of two bedding materials during the hot summer period. The study was focused on the research of water mattresses and straw bedding.

\section{Material and methods}

This study was carried during the summer season in 2017. The dairy farm is located in a mild climate zone in Topol'čany region. The farm is located in a mild climate zone. One of the five naturally ventilated barns was selected for the purposes of the pilot study. The barn was an older reconstructed building designed for 176 Holstein dairy cows. Average milking yield per one dairy cow was $22.92 \pm 2.85$ litres per day. There were head to head cubicles with dimensions $4 \times 22 \mathrm{~m}$ utilizing water mattresses on the left side and identical cubicles utilizing chopped straw on the right side. Water mattresses were cleaned once a day - in the morning during milking. Straw bedding was also changed once during milking. All alleys had grooved concrete surface.

Contact address: Michaela Némethová, Slovak University of Agriculture in Nitra, Faculty of Engineering, Slovakia, e-mail: xnemethova@is.uniag.sk 
Thermal properties of straw were investigated in a previous research, in which the thermal properties of organic bedding were determined (Lendelová et al., 2016).

\section{Theoretical calculation}

The theoretical calculation was based on theoretical foundations of thermal conductivity in materials. Base information for calculations contains the STN 73 0540$2+Z 1+Z 2$ (2019). Layers of stall base with materials were determined from the top to the bottom. Physical properties and formula for thermal effusivity calculation of all materials for every single layer were used from Chmúrny (2003).

General formula for floor thermal effusivity calculation is as follows:

$$
b=\sqrt{c \cdot \lambda \cdot \rho}, \mathrm{W} \cdot \mathrm{s}^{1 / 2} \cdot \mathrm{m}^{-2} \cdot \mathrm{K}^{-1}
$$

where:

$$
\begin{array}{ll}
c & \text { - specific heat capacity, } \mathrm{J}^{\mathrm{kgg}} \mathrm{kg}^{-1} \cdot \mathrm{K}^{-1} \\
\rho & - \text { bulk density, } \mathrm{kg} \cdot \mathrm{m}^{-3} \\
\lambda & - \text { coefficient of thermal conductivity, } \mathrm{W} \cdot \mathrm{m}^{-1} \cdot \mathrm{K}^{-1}
\end{array}
$$

Two layer equivalent effusivity $b^{* *}$; three layer equivalent effusivity $b^{* * *}$; and multi-layer equivalent effusivity use nondimensional coefficient $k_{x, y}$ where:

$$
k_{x, y}=2 \sum_{n=1}^{\infty}\left(\frac{x-1}{x+1}\right)^{n} \cdot e\left(-n^{2} y\right)
$$

where:

$K$ - non-dimensional quantity characterizing the degree of influence of the floor layer competent on the heat exchange of the floor structure:

$$
b^{* *}=b_{1}\left(1+K_{1,2}\right) \text { and } b^{* * *}=b_{1}\left(1+K_{1,2,3}\right)
$$

where:

$b_{1}$ - calculated on the basis of the top layer material properties

In addition, $U$ - heat transfer coefficient - is calculated using formula by Chmúrny (2003).

$$
U=\frac{1}{R}, \mathrm{~W} \cdot \mathrm{m}^{-2} \cdot \mathrm{K}^{-1}
$$

where:

$R=\frac{d}{\lambda}, \mathrm{m}^{2} \cdot \mathrm{K} \cdot \mathrm{W}^{-1}$

where:

$$
\begin{array}{ll}
R & - \text { thermal resistance, } \mathrm{m}^{2} \cdot \mathrm{K} \cdot \mathrm{W}^{-1} \\
d & - \text { thickness of layer, } \mathrm{m} \\
\lambda & - \text { coefficient of thermal conductivity, } \mathrm{W} \cdot \mathrm{m}^{-1} \cdot \mathrm{K}^{-1}
\end{array}
$$

\section{Climate data}

The climate data (air temperature and relative air humidity) were recorded by continuous measuring inside and outside of the barn using equipment COMET S-3121. For measurement of conditions during two hot summer months, 4 hours were selected (12:30-16:30) - the hottest hours of the day.

\section{Thermographic measurements}

The thermographic measurements were performed during two summer months. Measurements utilizing the thermocamera were always conducted when the outdoor temperature reached its peak - the period from 12:30 to 16:30. Thermograms of empty cubicles and cubicles after one hour of cow's lying (when the dynamics of temperature changes is already stabilized) were obtained using TP8S thermocamera with resolution $640 \times 480$ pixels.

Circular form was used for the same pixel area evaluation, recording thermocamera was placed at the top of the observed cubicle before each scanning. A new thermogram was scanned after the cow had lied down. To record the surface temperature, it was necessary that the cattle remained lying on the observed bedding types for a period of 60 to 70 minutes. The cow was disturbed from lying after this control time had passed, and the circle was immediately placed on the cubicle base where the animal has been lying (Figs. 1 and 2). Each thermogram was taken from the same height - lens of the thermocamera was always fixed at $1.80 \mathrm{~m}$ above the cubicle surface by a tripod. Tested cubicle surface could not be disturbed, either by thermocamera equipment or by human activity. Emissivity was set up for evaluated material. Selected samples did not include areas of straw and water mattresses feceated and/or urinated on, which would significantly change the physical properties of the observed surface. The program IS Guide IrAnalyser was used for thermogram scans evaluation.

\section{Statistical analysis}

Average surface temperature of empty cubicles and animal body prints was analysed utilizing ANOVA - one-way analysis

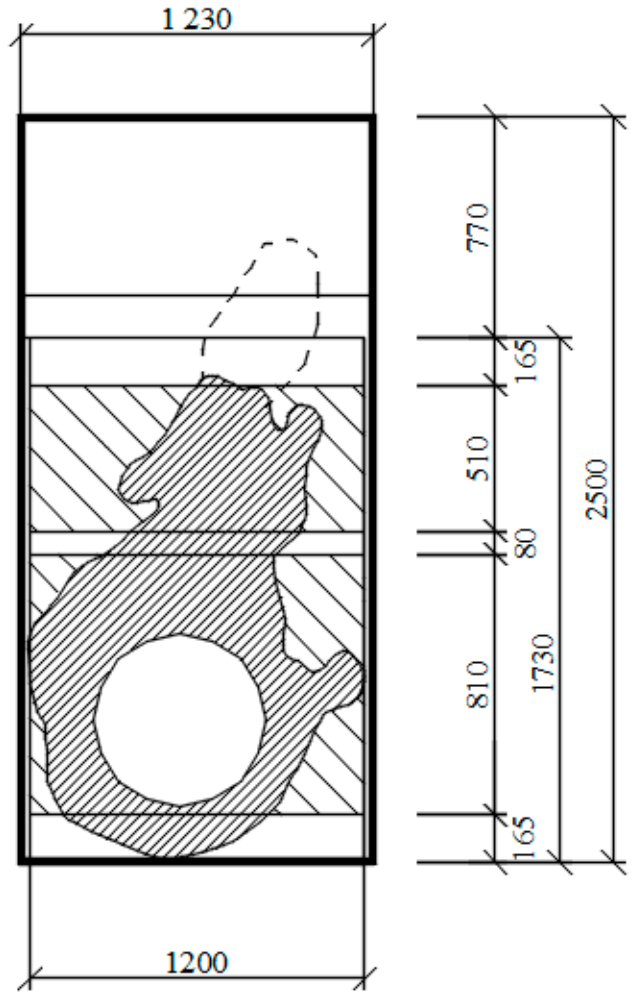

Fig. 1 Animal body print on the water mattress with auxiliary circle 


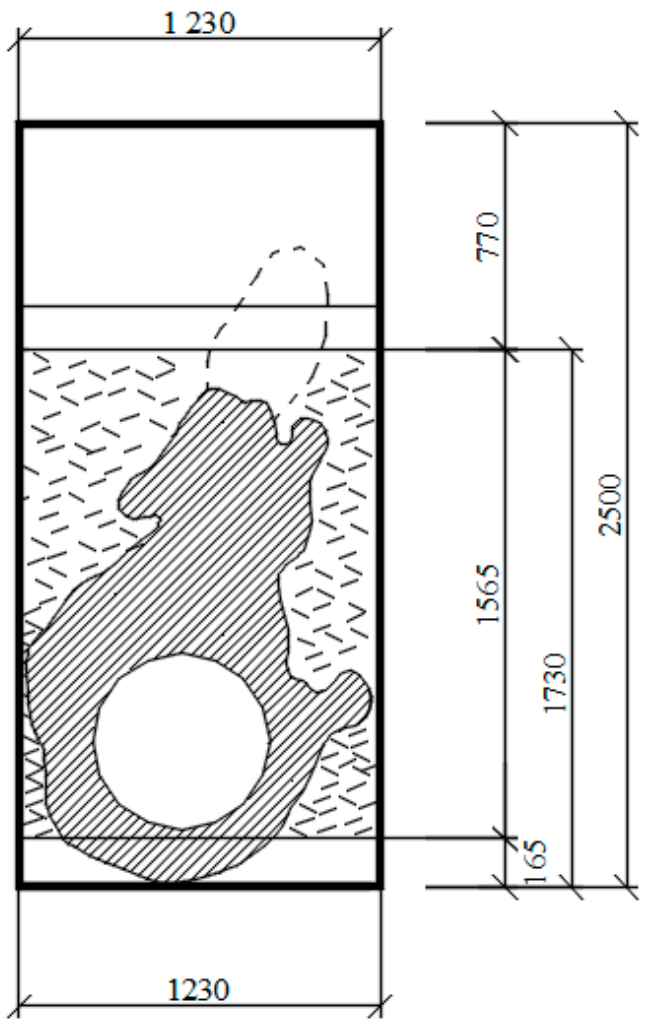

Fig. 2 Animal body print on the chopped straw with auxiliary circle

(STATISTICA 10, StatSoft CR s. r. o.). The factor was determined as a type of surface - water mattress and straw. There was also conducted a test of increasing the surface temperature before and after lying, in which the factor was temperature before and after lying. The significance of factors in ANOVA was performed by $T$-test. Differences between indoor and outdoor air temperature, as well as air relative humidity for summer months, were tested by means of independent samples T-test (STATISTICA 10, StatSoft CR s. r. o.).

\section{Results and discussion}

\section{Thermo-technical calculations}

Results of thermo-technical calculations are presented in Table 1.
According to the calculations, straw showed more than 3 times lower thermal effusivity, indicating that it removes more than 3 times less heat from the cow's body in contrast to water mattress. Insulating properties of straw bedding with a thickness of $200 \mathrm{~mm}$ is better described by the heat transfer coefficient, which is approximately 12.5 times lower than for water mattress.

\section{Climate data}

Significant difference $(p<0.05)$ was observed between the outdoor and indoor air temperatures: it was lower in the stable. On the other hand, the relative air humidity in stable was significantly higher $(p<0.05)$ in comparison to the outdoor air humidity.

Table 2 Average outdoor and indoor data values during the monitoring period

\begin{tabular}{|l||c|}
\hline \multicolumn{2}{|l||}{ Climate parameters } \\
\hline \multicolumn{2}{|l|}{ Average air temperature $\left({ }^{\circ} \mathbf{C}\right)$} \\
\hline Outdoor & $35.41 \pm 0.60$ \\
\hline Indoor & $32.55 \pm 0.53^{*}$ \\
\hline Average relative air humidity (\%) \\
\hline Outdoor & $27.37 \pm 2.32$ \\
\hline Indoor & $34.43 \pm 3.50^{*}$ \\
\hline${ }^{*} p<0.05$ & \\
\hline
\end{tabular}

\section{Thermographic measurements}

Thermal calculations were tested by means of thermographic measurements under the farm conditions. These results are shown in Table 3.

Before the animal had lied down, water mattress surface temperature was found out lower than straw bedding surface temperature. After one hour of cow's lying, the difference in temperatures between materials was statistically significant $(p<0.05)$. The surface temperature of straw bedding was higher $(p<0.05)$ in contrast to water mattress temperature. The surface temperature of straw significantly increased $(p<0.05)$ after prolonged laying, whereas water mattress temperature did not show any significant increase.

Thermo-technical parameters necessary for calculation of the thermal effusivity $b$, and heat transfer coefficient $U$, coefficient of thermal conductivity $\lambda$, specific heat capacity $c$, bulk density $\rho$ are different for bedded and no-bedded cubicles; this also affects their suitability and acceptability

Table 1 Results of thermo-technical stall base layer calculations

\begin{tabular}{|c|c|c|c|c|c|c|}
\hline Type of stall base & Number of layer & Material & $d(\mathrm{~m})$ & $\lambda\left(\mathbf{W} \cdot \mathbf{m}^{-2} \cdot \mathbf{K}^{-1}\right)$ & $b\left(W \cdot s^{1 / 2} \cdot m^{-2} \cdot K^{-1}\right)$ & $U\left(W \cdot m^{-2} \cdot K^{-1}\right)$ \\
\hline \multirow{4}{*}{$\begin{array}{l}\text { Water mattress } \\
\text { on concrete }\end{array}$} & 1 & rubber & 0.003 & 0.10 & \multirow{4}{*}{572.46} & \multirow{4}{*}{4.504} \\
\hline & 2 & water & 0.035 & 0.60 & & \\
\hline & 3 & rubber & 0.003 & 0.10 & & \\
\hline & 4 & concrete & 0.150 & 1.43 & & \\
\hline \multirow{2}{*}{ Straw on concrete } & 1 & straw & 0.200 & 0.06 & \multirow{2}{*}{173.55} & \multirow{2}{*}{0.36} \\
\hline & 2 & concrete & 0.150 & 1.22 & & \\
\hline
\end{tabular}

$U_{w m, r w r}=8.51 \mathrm{~W} \cdot \mathrm{m}^{-2} \cdot \mathrm{K}^{-1}$ (rubber, water, rubber); $U_{s}=0.34 \mathrm{~W} \cdot \mathrm{m}^{-2} \cdot \mathrm{K}^{-1}($ straw $) ; U_{c}=9.53 \mathrm{~W} \cdot \mathrm{m}^{-2} \cdot \mathrm{K}^{-1} ; b_{(c)}=1,882,02 \mathrm{~W} \cdot \mathrm{s}^{1 / 2} \cdot \mathrm{m}^{-2} \cdot \mathrm{K}^{-1}$ (concrete) 
Table 3 Average surface temperatures of the bedding types

\begin{tabular}{|l||c|c|c|}
\hline \multicolumn{1}{|c|}{} & \multicolumn{3}{|c|}{ Average surface temperature $\left({ }^{\circ} \mathrm{C}\right)$} \\
\cline { 2 - 4 } & before lying & after lying & difference \\
\hline Straw & $32.77 \pm 1.76$ & $35.88 \pm 0.38$ & $3.11 \pm 1.94^{*}$ \\
\hline Water mattress & $29.67 \pm 1.13$ & $30.93 \pm 0.82$ & $1.26 \pm 1.42$ \\
\hline difference & $3.1 \pm 1.88^{*}$ & $4.95 \pm 1.09^{*}$ & \\
\hline
\end{tabular}

${ }^{*} p<0.05$

for summer and winter. Considering the $U$ (heat transfer coefficient), the smaller the value, the better the thermal insulation structure properties. It was observed that the most suitable material in terms of $U$ was concrete $(U=$ $\left.9.53 \mathrm{~W} \cdot \mathrm{m}^{-2} \cdot \mathrm{K}^{-1}\right)$, which allows the heat to dissipate from the animal body most efficiently in summer; however, it is disadvantageous in winter. All in all, it is a hard and formless material and thus unsuitable for the purposes of a surface for resting cows. Considering straw, $U$ was 12.5 times lower than in water mattress, suggesting that chopped straw is more suitable bedding material for winter.

Similarly, in relation to evaluation of $b$ - thermal effusivity - the higher the values, the faster the heat dissipation. Concrete is the most suitable material for lying in summer $\left(b=1,882.02 \mathrm{~W} \cdot \mathrm{s}^{1 / 2} \cdot \mathrm{m}^{-2} \cdot \mathrm{K}^{-1}\right)$ in this aspect. Water mattresses did not show high $b$ when situated on the concrete stall base; however, this value was 3 times higher for water mattresses than for straw $\left(b=173.55 \mathrm{~W} \cdot \mathrm{s}^{1 / 2} \cdot \mathrm{m}^{-2} \cdot \mathrm{K}^{-1}\right)$. Straw provides the fastest adaptation of the cow contact body temperature in winter. The range between termotechnical values was wide for steady state $(U$ from 0.36 to $9.5 \mathrm{~W} \cdot \mathrm{m}^{-2} \cdot \mathrm{K}^{-1} ; b$ from 173.55 to $\left.1,882.02 \mathrm{~W} \cdot \mathrm{s}^{1 / 2} \cdot \mathrm{m}^{-2} \cdot \mathrm{K}^{-1}\right)$, we evaluated the effect of the dynamics of changes in physical properties on the surface under field summer conditions. When the animals lie, there is a direct contact between the body and the stall base, which allows the heat exchange by the conductivity during each lying, which is $8-16$ hours a day (Haley et al., 2000). Conductive cooling is one of the four ways of heat exchange available to cows to transfer the metabolic heat they produce to the environment. It involves the heat flow from the skin down a thermal gradient to a surface that has a lower temperature in summer (Ortiz et al., 2014). When a cow lies on water mattress, mattress surface temperature is cooler than the cow's skin, which allows transfer the heat from the body into the water inside the mattress (Lendelová et al., 2017). In practice, water mattress surface temperature provides a cooler lying surface before the cow lies on it. The initial straw surface temperature was higher than water mattress surface temperature and increased by $3.11 \pm 1.94^{\circ} \mathrm{C}$ after 1 hour of lying. The cow core body temperature is $38.59 \pm 0.48{ }^{\circ} \mathrm{C}$ (Iwasaki et al., 2019); assuming the surface temperature of cows is approx. $35^{\circ} \mathrm{C}$, the temperature difference between the cow's body surface and water mattress surface is significantly higher after one hour of lying $\left(4.1^{\circ} \mathrm{C}\right)$ than in case of lying on the chopped straw (surface temperature of the straw is approx. $0.9^{\circ} \mathrm{C}$ higher), the contact temperature area of which quickly adjusted. Water in mattresses has high thermal capacity and allows heat accumulation from air, ground and animals at slower rate than straw. Bastian et al. (2003) have proved that water temperature in mattresses can vary depending on time cows spent lying on the mattress. During warm days, water-filled mattresses as a bedding surface can reduce the heat load with their local cooling when the cow rests on the mattress depending on the duration of its lying. Manninen et al. (2002) have found that straw cubicles were occupied significantly more frequently than sand cubicles during both winter and summer. Thanks to straw bedding, the time that cows spent lying increased, and cows preferred straw stalls to sand stalls (Norring et al., 2008). There are only a few studies aimed at the conductive cooling efficiency evaluation during the summer period. Merely $20 \%$ of the cow's body surface is capable of heat exchange by conduction (Ortiz et al., 2014). Furthermore, Bastian et al. (2003) observed that only 19\%. Measurements presented showed that, in some cases, the average body print surface temperature was slightly lower in contrast to the part unoccupied by the animal. It is possible that non-absorbent rubber surface creates a barrier for the emerging animal sweat, which can cause a print of micro-sweating. Its thermal respond can ultimately cause temperature drop accordingly to the wet surface, which is not perceptible by the human eye when working with a thermocamera. Sweating is a major, if not the most important, thermoregulatory mechanism used to dissipate excess body heat (Silanikove, 2000; Kadzere et al., 2002). There are two types of sweating that occur in dairy cows, both are appreciably involved in heat dissipation. The first type is insensible sweating - perspiration - that takes place constantly, unless the relative humidity is $100 \%$. The other type - thermal sweating - occurs as a principle evaporative cooling mechanism of cow when ambient temperature rises. The heat required to convert water into vapour is referred to as the latent heat of vaporization. The proportion of metabolic heat that is dissipated from cow by evaporation increases with rising environmental temperature and a decreasing temperature gradient between the animal and air. Cattle showed appreciable increase in evaporative between 15 and $20^{\circ} \mathrm{C}$ with rise in environmental temperature; the maximum rate of evaporative cooling was reached before $30^{\circ} \mathrm{C}$ (Kadzere et al., 2002). Therefore, animal under heat stress are more sweating, what results in increased body fluid loss (Das et al., 2016). Heat loss by conductivity leads to increased water temperature in mattresses (Wadsworth et al., 2015; Bastian et al., 2003). Perano et al. (2015) investigated lowering of cow body temperature by means of cooling with circulating water in water mattress at $10{ }^{\circ} \mathrm{C}$ and $4.5^{\circ} \mathrm{C}$ and found that rectal temperature of cows was lower by $0.3^{\circ} \mathrm{C}$ when they were cooled with $4.5^{\circ} \mathrm{C}$ circulating water in contrast to $10^{\circ} \mathrm{C}$ circulating water; other variables taken into account did not show any significant difference between these two cooling temperatures. When cows were conductively cooled using $4.5^{\circ} \mathrm{C}$ circulating water, rectal temperature decreased by $1.0{ }^{\circ} \mathrm{C}$; respiration rate decreased by $18 \mathrm{bpm}$; milk yield 
increased by $5 \%$; and DMI increased by $14 \%$ in comparison to the control herd. However, utilization of conductively cooled water mattresses is economically questionable in mild climate zone.

\section{Conclusions}

The purpose of this study was to theoretically and practically observe thermo-technical properties of two bedding materials during the hot summer period in mild climate of Slovakia under the field conditions. On the basis of theoretical evaluation of the thermo-technical properties of the design of cow cubicles, it was observed that elevated concrete stall base cubicles covered with water mattresses belong to the group of inadequately warm floors, while deepened concrete stall base cubicles filled with straw belong to the group of very warm floors with thermal effusivity lower than $b=350$ $\mathrm{W} \cdot \mathrm{s}^{1 / 2} \cdot \mathrm{m}^{-2} \cdot \mathrm{K}^{-1}$. Since this theoretical assessment in accordance with the standard calculations considers a constant state and takes into account neither climatic conditions nor dynamic changes in the cubicle surface, both types of cubicle surfaces have been investigated under field conditions.

Based on thermographic measurements under field conditions of dairy farm, the surface temperature of water mattresses was lower by $3.1 \pm 1.88{ }^{\circ} \mathrm{C}$ in comparison to the straw bedding before the cattle lied on these surfaces. The temperature difference measured after an hour of lying on water mattress was lower by $4.95 \pm 1.09{ }^{\circ} \mathrm{C}$ than on chopped straw. The straw surface temperature after an hour of lying is very close to the animal core temperature (average straw surface temperature was $35.88 \pm 0.38{ }^{\circ} \mathrm{C}$ ), which almost prevents the heat transfer from the cow body while lying during hot days. Higher temperature difference between animal body and water mattress surface creates a better environment for heat dissipation during hot summer days in Slovakia.

All in all, practical measurements should be emphasized, because it is better to take into account the values of thermal effusivity $b$ from the point of view of physical calculations, since these values provide better description of the temporal development of surface temperatures during their occupation by cattle.

On the basis of aforementioned, emphasis is placed on other knowledge for verifying the water mattresses and chopped straw in practice according to the quality and state of cubicle, and different thermal-humidity conditions.

\section{References}

BASTIAN, K. R. - GEBREMEDHIN, K. G. - SCOTT, N. R. 2003. A finite difference model to determine conduction heat loss to a waterfilled mattress for dairy cows. In Transactions of the ASAE, vol. 46, no. 3, pp. 773-780.

COOK, N. B. - MENTINK, R. L. - BENNETT, T. B. - BURG, K. 2007. The effect of heat stress and lameness on time budgets of lactating dairy cows. In Journal of Dairy Science, vol. 90, no. 4, pp. 1674-1682. DAS, R. - SAILO, L. - VERMA, N. - BHARTI, R. - SAIKIA, J. - IMTIWATI KUMA, R. 2016. Impact of heat stress on health and performance of dairy animals. In A review. Veterinary World, vol. 9, no. 3, pp. 2.

HALEY, D. B. - RUSHEN, J. - PASSILLÉ, de. M. A. 2000. Behavioural indicators of cow comfort: Activity and resting behaviour of dairy cows in two types of housing. In Canadian Journal of Animal Science, vol. 80, pp. 257-263.
CHMÚRNY, I. 2003. Heat Protection of Buildings. bratislava : jaga Group, 2003. 214 pp. ISBN 80-88905-27-3 (In Slovak: Tepelná ochrana budov).

IWASAKI, W. - ISHIDA, S. - KONDO, D. - ITO, Y. - TATENO, J. TOMIOKA, M. 2019. Monitoring of the core body temperature of cows using implantable wireless thermometers. In Computers and Electronics in Agriculture, vol. 163, pp. 104849.

KADZERE, C. T. - MURPHY, M. R. - SILANIKOVE, N. - MALTZ, E. 2002. Heat stress in lactating dairy cows: A review. In Livestock Production Science, vol. 77, no. 1. pp. 59-91.

KULL, J. A. - INGLE, H. D. - BLACK, R. A. - EBERHART, N. L. - KRAWCZEL, P. D. 2017. Effects of bedding with recycled sand on lying behaviors, udder hygiene, and preference of lactating Holstein dairy cows. In Journal of Dairy Science, vol. 100, no. 9, pp. 7379-7389.

LENDELOVÁ, J. 2004. Floor Constructions as an Important Phenomenon in Stables for Cattle and Pigs. Nitra : SUA. 184 pp. (dissertation thesis).

LENDELOVÁ, J. - KARANDUŠOVSKÁ, I. - ŽITŇÁK, M. - BOĎO, Š. MIHINA, Š. 2017. Effect of climatic conditions on differences in thermo-technical properties of organic bedding in laboratory testing. In Acta Technologica Agriculturae, vol. 20, no. 1, pp. 1-6.

LENDELOVÁ, J. - POGRAN, Š. - BOŽIKOVÁ, M. - PÁLEŠ, D. 2009. Simulation of heat conduction in natural and synthetic cow lying floors during wintertime. In Acta Technologica Agriculturae, vol. 12, no. 1, pp. 13-14.

LENDELOVÁ, J. - ŽITŇÁK, M. - BOŠANSKÝ, M. - ŠIMKO, M. - PITERKA, P. 2016. Testing of property changes in recycled bedding for dairy cows. In Research of Agricultural Engineering, vol. 62, pp. 44-52.

MANNINEN, E. - PASSILLÉ, de A. M. - RUSHEN, J. - NORRING, M. SALONIEMI, H. 2002. Preference of dairy cows kept in unheated buildings for different kind of cubicle flooring. In Applied Animal Behaviour Science, vol. 75, no. 4, pp. 281-292.

MARGERISON, J. K. - LAU, J. - HEDLEY, M. J. - HORNE, D. J. - HANLY, J. A. -POWELL, N. - SHILTON, A. 2014. Lying and feeding behavior of dairy cows at pasture and housed in free stalls fitted with sand and water filled mats. In Occasional Report no. 27.

NORRING, M. - MANNINEN, A. - PASSILLÉ, de M. - RUSHEN, J. MUNKSGAARD, L. - SALONIEMI, H. 2008. Effects of sand and straw bedding on the lying behavior, cleanliness, and hoof and hock injuries of dairy cows. In Journal of Dairy Science, vol. 91, no. 2, pp. 570-576.

PERANO, M. K. - USACK, G. J. - ANGENENT, L. T. - GEBREMEDHIN, K. G. 2015. Production and physiological responses of heat-stressed lactating dairy cattle to conductive cooling. In Journal of Dairy Science, vol. 98, no. 8, pp. 5252-5261.

ORTIZ, X. A. - SMITH, J. F. - ROJANO, F. - CHOI, C. Y - BRUER, J. - STEELE, T. - SCHURING, N. - ALLEN, J. - COLLIER, R. J. 2014. Evaluation of conductive cooling of lactating dairy cows under controlled environmental conditions. In Journal of Dairy Science, vol. 98 , no. 3, pp. 1759-1771.

SILANIKOVE, N. 2000. Effects of heat stress on the welfare of extensively managed domestic animals. In Livestock Production Science, vol. 67, no. 1-2, pp. 1-18.

STN $730540-2+Z 1+Z 2$. 2019. Thermal protection of buildings. Thermal performance of buildings and components. Part 2: Functional requirements. (Slovak technical standard)

TUCKER, C. B. - WEARY, D. M. - FRASER, D. 2003. Effects of three types of free-stall surfaces on preferences and stall usage by dairy cows. In Journal of Dairy Science, vol. 86, no. 2. pp. 521-529.

WADSWORTH, B. A. - STONE, A. E. - CLARK, J. D. - RAY, D. L. BEWLEY, J. M. 2015. Stall cleanliness and stall temperature of two different freestall bases. In Journal of Dairy Science, vol. 98, no. 6, pp. 4206-4210.

WEST, J. W. 2003. Effects of heat-stress on production in dairy cattle. In Journal of Dairy Science, vol. 86, no. 6. pp. 2131-2144.

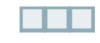

